\title{
The epidemiology of cutaneous malignant melanoma in Nova Scotia
}

\author{
Andrew L Howlett BSc ${ }^{1}$, Ron AD Dewar MSc ${ }^{2}$, Steven F Morris MD MSc FRCSC ${ }^{1}$
}

\begin{abstract}
AL Howlett, RAD Dewar, SF Morris. The epidemiology of cutaneous malignant melanoma in Nova Scotia. Can J Plast Surg 2006;14(4):211-214.
\end{abstract}

BACKGROUND: Since 1993, the annual increase in cutaneous malignant melanoma (MM) incidence has been one of the highest for all cancers registered in Canada, with the leading rate in Nova Scotia (NS). The purpose of the present study was to document the pathological and epidemiological data on MM cases found in NS.

PATIENTS AND METHODS: All MM cases identified by the Nova Scotia Cancer Registry from January 1998 to December 2002 were evaluated. The five-year survival outlook, by major prognostic factors, was also determined. In addition, the annual incidence and mortality rates from 1972 to 2002 were computed.

RESULTS: Between 1998 and 2002, 925 MM cases were recorded. The age-standardized incidence rate for males and females in this period was 19.2 and 16.1 per 100,000 respectively. Men 65 years of age or older had the highest age-specific rate. The most common MM had a Breslow's depth of less than $1.0 \mathrm{~mm}(61.9 \%)$ and was Clark's level II (34.9\%). There was no significant seasonal variation noted in the time of diagnosis. Survival analyses indicated that sex, age, tumour location and thickness were significant independent predictors. Despite the increase in incidence, there have only been modest changes in the annual mortality rate.

CONCLUSION: The incidence of MM in NS increases with age, and is nearly double for men 65 years of age or older, compared with women in the same age group. Thin melanomas on the extremities of young females have the best prognosis in NS, which is similar to other parts of the world. Incidence appears to be unrelated to season. Public health interventions are necessary to reduce the burden of this disease.

Key Words: Canada; Cancer registry; Epidemiology; Melanoma; Nova Scotia

\section{L'épidémiologie du mélanome cutané malin en Nouvelle-Écosse}

HISTORIQUE : Depuis 1993, l'augmentation annuelle de l'incidence du mélanome cutané malin (MM) est l'une des plus élevée de tous les cancers recensés au Canada, le taux le plus fort s'observant en NouvelleÉcosse (NÉ). La présente étude visait à documenter les données pathologiques et épidémiologiques des cas de MM en Nouvelle-Écosse. PATIENTS ET MÉTHODOLOGIE : Tous les cas de MM dépistés par le registre des cancers de la Nouvelle-Écosse entre janvier 1998 et décembre 2002 ont été évalués. La perspective de survie au bout de cinq ans par principaux facteurs pronostiques a également été déterminée. De plus, l'incidence et les taux de mortalité annuels ont été calculés entre 1972 et 2002.

RÉSULTATS : Entre 1998 et 2002, 925 cas de MM ont été enregistrés. Pendant cette période, le taux d'incidence normalisé selon l'âge pour les hommes et les femmes s'élevait à 19,2 et 16,1 pour 100000 habitants, respectivement. Les hommes de 65 ans et plus avaient le taux le plus élevé par âge. Les cas les plus courants de MM s'associaient à un indice de Breslow de moins de 1,0 mm (61,9\%) et à un niveau de Clark II (34,9\%). On ne remarquait aucune variation saisonnière significative du diagnostic. Les analyses de survie indiquaient que le sexe, l'âge, le foyer et l'épaisseur de la tumeur constituaient d'importants prédicteurs indépendants. Malgré l'augmentation d'incidence, les modifications au taux de mortalité annuel étaient modestes.

CONCLUSION : L'incidence de MM en NÉ augmente avec l'âge et est pratiquement deux fois plus élevée chez les hommes de 65 ans et plus que chez les femmes du même groupe d'âge. Les mélanomes de faible épaisseur aux extrémités des membres des jeunes femmes s'associent au meilleur pronostic en NÉ. Ce résultat est similaire à celui observé ailleurs dans le monde. L'incidence ne semble pas reliée à la saison. Des interventions s'imposent en santé publique pour réduire le fardeau de cette maladie.

Amanificant increase in the incidence of cutaneous
Caucasian populations in North America, Europe and
Australia (1-3). The most recent public data on the incidence
of MM in Canada were reported in 2001 by Cancer
Surveillance On-line (3), reporting an age-standardized
incidence rate (ASIR) of 12.6 and 10.2 per 100,000 males and
females, respectively. This same report also indicated that, on a
provincial basis, Nova Scotia (NS) had the highest annual
incidence rate (16.4 per 100,000) of MM in males and was
second to the annual incidence rate of MM in Prince Edward
Island in females (NS 13.8 per 100,000 females) (3). Since
1993, the annual increase in the incidence of MM has been
one of the highest for both sexes among all cancers in Canada
(3). The purpose of the present study was to examine the
pathological and epidemiological data on MM in NS from
January 1998 to December 2002 . The long-term incidence and

mortality trends along with a five-year survival outlook were also determined.

\section{PATIENTS AND METHODS}

The Nova Scotia Cancer Registry (NSCR) collects data on all cancer cases in NS according to nationally recognized standards. Reporting sources include provincial pathology laboratories, hospital health record departments, physician offices, provincial cancer centres, NS vital certificates and other Canadian registries (2). All tumours diagnosed are classified by histology and tumour location by the International Classification of Diseases for Oncology (2).

All cases of invasive MM from January 1998 to December 2002 were analyzed for the present study. In 2002, the population of NS was approximately 935,000 people. Cases of melanoma in situ were excluded. The date of the surgery, as recorded on the pathology report, was used as the date of diagnosis.

${ }^{1}$ Department of Surgery, Division of Plastic and Reconstructive Surgery, QEII Health Sciences Centre; ${ }^{2}$ Surveillance and Epidemiology Unit, Cancer Care, Nova Scotia, Halifax, Nova Scotia

Correspondence: Mr Andrew L Howlett, QEII Health Sciences Centre - Halifax Infirmary Site, 1796 Summer Street, Room 4443, Halifax, Nova Scotia B3H 3A7. Telephone 902-473-7054, fax 902-473-8773, e-mail alhowlet@dal.ca 
TABLE 1

Five-year descriptive statistics for cutaneous malignant melanoma in Nova Scotia from 1998 to 2002

\begin{tabular}{|c|c|c|c|}
\hline Parameter & $\begin{array}{c}\text { Males } \\
\text { n (\%) }\end{array}$ & $\begin{array}{c}\text { Females } \\
\mathbf{n}(\%)\end{array}$ & $\begin{array}{l}\text { Total } \\
\text { n (\%) }\end{array}$ \\
\hline Total number & $473(51.1)$ & $452(48.9)$ & $925(100)$ \\
\hline \multicolumn{4}{|l|}{ Age groups in years } \\
\hline $0-44$ & $73(15.4)$ & $112(24.8)$ & $185(20.0)$ \\
\hline $45-64$ & $188(39.7)$ & $176(38.9)$ & $364(39.4)$ \\
\hline$\geq 65$ & $212(44.8)$ & $164(36.3)$ & $376(40.6)$ \\
\hline \multicolumn{4}{|l|}{ Breslow's thickness } \\
\hline$<1.0 \mathrm{~mm}$ & $268(56.7)$ & $305(67.5)$ & $573(61.9)$ \\
\hline $1.0 \mathrm{~mm}$ to $4.0 \mathrm{~mm}$ & $143(30.2)$ & $91(20.1)$ & $234(25.3)$ \\
\hline$>4.0 \mathrm{~mm}$ & $32(6.8)$ & $15(3.3)$ & $47(5.1)$ \\
\hline Not reported & $30(6.3)$ & $41(9.1)$ & $71(7.7)$ \\
\hline Clark's level & $n=480$ & $n=445$ & \\
\hline I & $3(0.6)$ & $4(0.9)$ & $7(0.8)$ \\
\hline II & $151(31.9)$ & $172(38.1)$ & $323(34.9)$ \\
\hline III & $149(31.5)$ & $120(26.5)$ & $269(29.1)$ \\
\hline IV & $94(19.9)$ & $79(17.5)$ & $173(18.7)$ \\
\hline V & $16(3.4)$ & $10(2.2)$ & $26(2.7)$ \\
\hline$X$ - unknown & $60(12.7)$ & $67(14.8)$ & $127(13.7)$ \\
\hline \multicolumn{4}{|l|}{ Tumour site (ICD-10 code) } \\
\hline Head and neck (C43.0-4) & $126(26.6)$ & $83(18.4)$ & $209(22.6)$ \\
\hline Trunk (C43.5) & $201(42.5)$ & $98(21.7)$ & $299(32.3)$ \\
\hline Extremities $(\mathrm{C} 43.6,7)$ & $144(30.4)$ & $269(59.5)$ & $413(44.7)$ \\
\hline Skin, not specified (C43.9) & $2(0.4)$ & $2(0.4)$ & $4(0.4)$ \\
\hline \multicolumn{4}{|l|}{ Time of diagnosis } \\
\hline January to March & $129(27.3)$ & $95(21.0)$ & $224(24.2)$ \\
\hline April to June & $124(26.2)$ & $96(21.2)$ & $220(23.8)$ \\
\hline July to September & $121(25.6)$ & $147(32.5)$ & $268(29.0)$ \\
\hline October to December & $99(20.9)$ & $114(25.2)$ & $213(23.0)$ \\
\hline
\end{tabular}

ICD International Classification of Diseases

The data were analyzed separately for males and females, and were stratified into the following age groups - zero to 44 years of age, 45 to 64 years of age and 65 years of age or older. ASIRs per 100,000 persons were calculated by the direct method, using the 1991 Canadian population standard. ASIRs and mortality trends from 1972 to 2002 were determined using the NSCR data. The survival outlook for patients classified by tumour site, Breslow's depth, sex and age were calculated using the Kaplan-Meier method with associated log-rank significance tests. Multivariate modelling using Cox's proportional hazards model assessed the independent prognostic effect of these factors. All survival analyses were carried out using SAS version 9.1 (SAS Institute Inc, USA). The period of survival analysis was 1996 to 2002, commencing the year that Breslow's depth was included in the NSCR. Ethical approval of the present study was granted by the Capital District Health Authority Research Ethics Board.

\section{RESULTS}

Between 1998 and 2002, a total of 925 primary cases diagnosed as 'invasive MM of the skin' through histological examination were recorded in the NSCR. During this five-year period, MM was more frequent in males $(51.1 \%)$ than in females $(48.9 \%)$ (Table 1). The ASIR of MM per 100,000 was determined for both sexes for three age groups - zero to 44 years of age, 45 to 64 years of age and those 65 years of age or older (Table 2).
TABLE 2

Age-specific incidence rates* of cutaneous malignant melanoma for Nova Scotia from 1998 to 2002*

\begin{tabular}{lcc}
\hline Age group (years) & Males per $\mathbf{1 0 0 , 0 0 0}$ & Females per $\mathbf{1 0 0 , 0 0 0}$ \\
\hline $0-44$ & 5.0 & 7.8 \\
$45-64$ & 33.3 & 30.6 \\
$\geq 65$ & 80.0 & 44.9 \\
Total & 19.2 & 16.1 \\
\hline
\end{tabular}

*Based on the 1991 Canadian population standard

\section{TABLE 3}

Five-year survival probability of cutaneous malignant melanoma in Nova Scotia from 1996 to 2002

\begin{tabular}{lc}
\hline Survival factor & Five-year probability $(\%)$ \\
\hline Breslow's depth $\left(\mathrm{P}<0.0001^{*}\right)$ & 85.1 \\
$<1.0 \mathrm{~mm}$ & 65.2 \\
$1 \mathrm{~mm}$ to $4 \mathrm{~mm}$ & 34.2 \\
$>4 \mathrm{~mm}$ & \\
Tumour site $\left(\mathrm{P}<0.0002^{*}\right)$ & 79.9 \\
$\quad$ Extremities & 77.5 \\
Trunk & 61.5 \\
Head and neck & \\
Age in years $\left(\mathrm{P}<0.0001^{*}\right)$ & 88.0 \\
$<60$ & 63.2 \\
$\geq 60$ & \\
Sex $\left(\mathrm{P}<0.0001^{*}\right)$ & 82.5 \\
Female & 68.6 \\
Male & \\
\hline
\end{tabular}

${ }^{*} P$ value based on log-rank statistics

Females had a higher rate of MM (7.8 per 100,000) in the youngest age group compared with males $(5.0$ per 100,000$)$. However, in the oldest group, the incidence rate in males $(80.0$ per 100,000$)$ nearly doubled that of females $(44.9$ per 100,000). Overall, during this five-year period, the ASIR for males and females was 19.2 and 16.1 per 100,000 respectively.

Breslow's depth was divided into four categories, namely, thin (less than $1.0 \mathrm{~mm}$ ), moderate $(1.0 \mathrm{~mm}$ to $4.0 \mathrm{~mm}$ ), thick (greater than $4.0 \mathrm{~mm}$ ) and unreported. The majority of cases were thin $(56.7 \%$ in males and $67.5 \%$ in females), with only $7.7 \%$ of the total cases without identifiable thickness. Clark's level II was the most frequent, representing $34.9 \%$ of all cases.

The distribution of MM was significantly different between the sexes. The most common site observed in males was on the trunk $(42.5 \%)$, compared with females who had the highest proportion of lesions on their extremities (59.5\%). The majority of MM cases were recorded histologically as unspecified MMs (87.8\%). Other types including lentigo melanoma (LM), superficial spreading melanoma (SSM) and nodular melanoma (NM) were reported but with much less frequency $(0.11 \%$ to $3.24 \%)$.

The time of diagnosis based on the four seasons indicated that the majority of male cases were diagnosed in the first six months of the year $(53.5 \%)$ as opposed to females who were diagnosed more frequently in the last six months of the year $(57.5 \%)$.

The overall survival from 1996 to 2002 indicated significant differences at five years for all four factors studied (Table 3). For example, the five-year survival probability for 


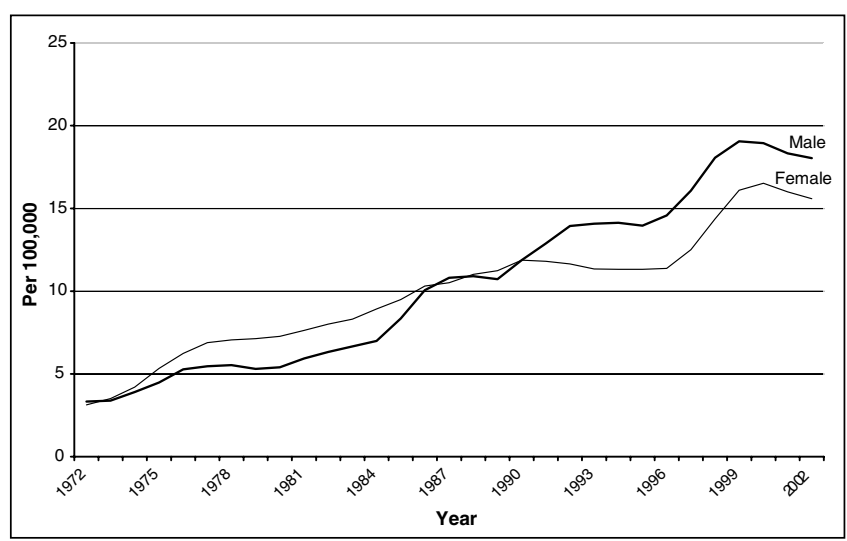

Figure 1) Age-standardized incidence rates of cutaneous malignant melanoma in Nova Scotia from 1972 to 2002. Annual rate plots have been smoothed using a three-year moving average method

thin melanomas (less than $1.0 \mathrm{~mm}$ ) was $85.1 \%$ compared with thick melanomas (greater than $4.0 \mathrm{~mm}$ ) at $34.2 \%$. In spite of correlation among these predictors (eg, between sex and location of lesion), multivariate modelling of survival confirmed an independent effect for each factor, although the independent effect of location was somewhat weaker when sex was accounted for in the model (results not presented).

The ASIR of MM per 100,000 female Nova Scotians has increased from 2.8 in 1972 to 15.9 in 2002 (Figure 1). The male ASIR has also risen from 3.2 in 1972 to 19.2 in 2002. The estimated annual per cent change in the ASIR over this time period is $6.2 \%$ for males and $3.5 \%$ for females $(\mathrm{P}<0.001)$. Figure 2 illustrates the trend in age-standardized mortality rates for the same time period. The estimated annual per cent change in mortality for males was $1.6 \%(\mathrm{P}<0.001)$ and $-1.4 \%$ $(\mathrm{P}=0.09)$ for females.

\section{DISCUSSION}

Over the past century, the incidence of MM has been increasing in most light-skinned populations worldwide (1). Both Canada and the United States report that the incidence of MM is rapidly rising compared with other types of cancers $(4,5)$.

The results of the present study are dependent on the consistent and accurate reporting of cases and the coding practices of the NSCR. Although reporting cases of melanoma to the registry is legally mandated, melanoma is also diagnosed in nonhospital medical settings, with under-reporting as high as $20 \%$ of the total cases in some cancer registries (5).

The group most at risk for developing MM in NS are men 65 years of age or older (incidence rate of 80 per 100,000). Similar male populations have the highest MM risk in the United States and Germany $(5,6)$. It has been recognized that females are often diagnosed at a younger age than males (7). However, in Australia where MM is the leading cause of cancer in individuals 15 to 44 years of age, the incidence is higher in males, reaching a rate of 50 per 100,000 in 1997 (1). The increase in incidence of $\mathrm{MM}$ with age is a pattern seen for most cancers in NS, and confirms that this population is most at risk and in need of further health promotion activities.

This is the first report on the Breslow's depth and Clark's level of MM in NS. The most common tumour identified between 1998 and 2002 was thin, with a Breslow's depth less

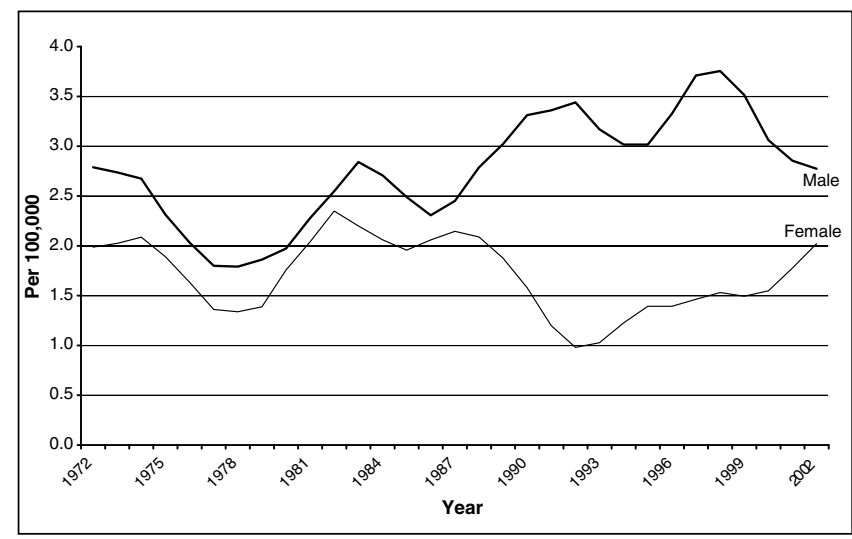

Figure 2) Age-standardized mortality rates of cutaneous malignant melanoma in Nova Scotia from 1972 to 2002. Annual rate plots have been smoothed using a three-year moving average method

than $1.0 \mathrm{~mm}(61.9 \%)$. Internationally, thin tumours are more common in western Europe than in eastern Europe (8); comparable data are not available in Canada. Patients presenting with thin MM may represent good patient awareness and early diagnosis in NS.

Similar to national (9-13) and international (7) studies, the anatomical distribution of MM in NS is unique for each sex. MMs are predominately more common on the trunk in males and on the extremities in females, and therefore, may be associated with the areas of sun exposure most common for each sex.

In the literature, the most common types of MM are SSM, LM and NM. Although there were some cases in NS identified as SSM, LM and NM, there was a high proportion of unspecified melanomas $(87.8 \%)$. Thus, greater efforts are needed to improve data quality because histological type may be an important factor in the treatment and prognosis of melanoma.

Although there is a slight difference between the majority of diagnoses in males (January to June) and females (July to December), MM is being recognized and treated all year round. Overall, on a quarterly basis, the summer months of July to September represent the majority of cases (29\%), with the fewest amount of cases being diagnosed from October to December (23\%). Seasonal variation has been analyzed on a larger scale in the United States, where it was observed that SSMs on the trunk and extremities were more frequently diagnosed in the summer and SSMs on the face and neck were diagnosed more frequently in the spring (14). Seasonal patterns have also been examined in Germany, where the ratio of summer to winter was 1.34 (95\% CI 1.27 to 1.43 ) (15). Possible explanations for the summer peak may be a greater awareness as a result of clothing habits or because of the influence of public health campaigns (15). Nevertheless, it is important to examine for MM throughout the year.

The present study evaluated four factors associated with patient survival (16-18). The results demonstrated thick MM on the head and neck, and showed that men 60 years of age or older have the worst five-year prognosis. Although females have a higher percentage of thin $\mathrm{MM}$ on the lower extremities diagnosed at an early age, controlling for all variables except sex predicts a better survival rate for females diagnosed with MM. In other jurisdictions, survival rates for patients with MM have increased over time (1). Trends in survival were not evaluated in the data. 
The trends calculated for NS during 1972 to 2002 demonstrated a significant increase in the number of $\mathrm{MM}$ cases reported to the NSCR. A similar pattern of increasing incidence, with only a modest change in mortality, was also observed in New Zealand, England and a number of other European countries (1).

The incidence rate of MM for males and females in NS between 1998 and 2002 was 19.2 and 16.1 per 100,000 , respectively. The most recent data available regarding the rest of Canada is from 1998 to 2001 (4). Over this period, the national ASIR for the male population was 12.12 per 100,000 males (4). The incidence rate of MM in males is the highest $(17.80$ per 100,000$)$ in NS, followed by Prince Edward Island (15.75 per 100,000$)$, Ontario (14.48 per 100,000$)$, New Brunswick (14.32 per 100,000), British Columbia (13.70 per $100,000)$, Alberta (13.15 per 100,000), Manitoba (11.30 per $100,000)$, Saskatchewan $(10.55$ per 100,000$)$, Newfoundland (7.62 per 100,000) and Quebec $(6.78$ per 100,000) (3). The most coastal and southern geographical locations generally have the highest incidence. The methods of reporting in other provinces may have been different and could explain the low incidence rate in Quebec.

\section{REFERENCES}

1. Bevona C, Sober AJ. Melanoma incidence trends. Dermatol Clin 2002;20:589-95, vii.

2. Saint-Jacques N, MacIntyre M, Dewar R, Johnston G. Cancer Statistics in Nova Scotia: A Focus on 1995-1999. Surveillance and Epidemiology Unit, Cancer Care Nova Scotia, 2002.

3. Public Health Agency of Canada. Cancer Surveillance On-line. $<$ http://dsol-smed.phac-aspc.gc.ca/dsol-smed/cancer/> (Version current at August 21, 2006).

4. Statistics Canada. Cancer Statistics 2004. <http://www.statcan.ca/english/freepub/84-601-XIE/84-601XIE2004001.htm > (Version current at August 21, 2006).

5. Jemal A, Devesa SS, Hartge P, Tucker MA. Recent trends in cutaneous melanoma incidence among whites in the United States. J Natl Cancer Inst 2001;93:678-83.

6. Buettner PG, Leiter U, Eigentler TK, Garbe C. Development of prognostic factors and survival in cutaneous melanoma over 25 years: An analysis of the Central Malignant Melanoma Registry of the German Dermatological Society. Cancer 2005;103:616-24.

7. Katalinic A, Kunze U, Schafer T. Epidemiology of cutaneous melanoma and non-melanoma skin cancer in Schleswig-Holstein, Germany: Incidence, clinical subtypes, tumour stages and localization (epidemiology of skin cancer). Br J Dermatol 2003;149:1200-6.

8. Boniol M, De Vries E, Coebergh JW, Dore JF; EUROCARE Working Group. Seasonal variation in the occurrence of cutaneous melanoma in Europe: Influence of latitude. An analysis using the EUROCARE group of registries. Eur J Cancer 2005;41:126-32.

\section{CONCLUSION}

The present paper provides the first analysis of populationbased data for MM in NS. Because the incidence of MM is rising and the incidence in NS is the highest in Canada, this is an important study population. The characteristics of this disease illustrate significant patterns and trends that should be observed and monitored.

The findings of the present study identified that the oldest population for both sexes was at the highest risk for developing $\mathrm{MM}$ and that it is more common for females to present with $\mathrm{MM}$ at a younger age. Such results may provide a foundation for further research, along with the development of public health interventions. Those interested in the study, treatment and prevention of MM, including family physicians, dermatologists, surgeons and pathologists, should work toward reporting all cases of $\mathrm{MM}$ and the details of these cases to the provincial registries.

ACKNOWLEDGEMENTS: The authors would like to acknowledge Cancer Care Nova Scotia and the Nova Scotia Cancer Registry for their support, as well as the Dalhousie Medical Research Foundation and the Dr W Alan Curry Studentship award for funding the present study.

9. Bulliard JL, Cox B, Elwood JM. Comparison of the site distribution of melanoma in New Zealand and Canada. Int J Cancer 1997;72:231-5.

10. Bulliard JL, Cox B, Semenciw R. Trends by anatomic site in the incidence of cutaneous malignant melanoma in Canada, 1969-93. Cancer Causes Control 1999;10:407-16.

11. Elwood JM, Gallagher RP. Site distribution of malignant melanoma. Can Med Assoc J 1983;128:1400-4.

12. Elwood JM, Gallagher RP. Body site distribution of cutaneous malignant melanoma in relationship to patterns of sun exposure. Int J Cancer 1998;78:276-80.

13. Gallagher RP, Ma B, McLean DI, et al. Trends in basal cell carcinoma, squamous cell carcinoma, and melanoma of the skin from 1973 through 1987. J Am Acad Dermatol 1990;23:413-21.

14. Chao C, Martin RC II, Ross MI, et al. Correlation between prognostic factors and increasing age in melanoma. Ann Surg Oncol 2004;11:259-64.

15. Schmid-Wendtner MH, Baumert J, Plewig G, Volkenandt M. Seasonal variations in the diagnosis of cutaneous melanoma. J Am Acad Dermatol 2004;50:679-82.

16. Schwartz SM, Armstrong BK, Weiss NS. Seasonal variation in the incidence of cutaneous malignant melanoma: An analysis by body site and histologic type. Am J Epidemiol 1987;126:104-11.

17. Schuchter L, Schultz DJ, Synnestvedt M, et al. A prognostic model for predicting 10-year survival in patients with primary melanoma. The Pigmented Lesion Group. Ann Intern Med 1996;125:369-75.

18. Crocetti E, Carli P. Only superficial spreading melanoma is causing the melanoma epidemics? Eur J Epidemiol 2004;19:91-2. 